\title{
ARGUMENTACIÓN Y PERSUASIÓN EN LOS ANUNCIOS COMERCIALES AUDIOVISUALES POST-CONFINAMIENTO: EL STORYTELLING
}

\author{
Laura MARIOTTINI \\ Sapienza Università di Roma (Italia)
}

\section{RESUMEN}

El presente trabajo, enmarcado en las líneas teóricas de los estudios sobre storytelling (Salmon 2008; Lamarre 2019) y de la argumentación y persuasión en el discurso (Gutiérrez Ordóñez 2000; Fuentes y Alcaide 2007), analiza un corpus de anuncios comerciales audiovisuales en español transmitidos tras la entrada en vigor del confinamiento del mes de marzo de 2020, con el propósito de analizar cómo se construye la argumentación y cuáles son las estrategias persuasivas de las que se sirven las marcas comerciales.

Mediante una metodología de análisis cualitativo basado en la interrogación cuantitativa de los textos, llevamos a cabo un estudio para destacar algunos de los mecanismos lingüísticos que contribuyen a la construcción de los actores y del escenario de la narración, así como también al avance de la acción narrativa. Concretamente, nos centramos en los recursos léxicos, pragmáticos y retóricos.

Con este trabajo de carácter intersticial y exploratorio entre lingüística y storytelling esbozamos una línea de estudio nueva e interdisciplinaria en la que, a partir de los resultados obtenidos, seguiremos profundizando, también desde ámbitos y contextos distintos.

PALABRAS CLAVE: storytelling; argumentación y persuasión en publicidad; anuncios audiovisuales.

\section{ABSTRACT}

The present paper, framed in the theoretical principles of the studies on storytelling (Salmon 2008; Lamarre 2019) in conjunction with the analysis of argumentative and persuasive texts (Gutiérrez Ordóñez 2000; Fuentes and Alcaide 2007), studies a corpus of audiovisual advertisements in Spanish, broadcast after the entry into force of the confinement on March 2020 in order to explore how the argumentation is built and what the persuasive strategies that commercial brands use are.

Using a qualitative method of the analysis based on a quantitative survey, we have carried a study to highlight those linguistic mechanisms that contribute to 
the construction of the actors, the narrative setting, and the action development. Specifically, we focus on lexical, pragmatic and rhetorical resources.

With this interstitial and exploratory work between linguistics and storytelling, we outline a new and interdisciplinary line of study which, in the light our findings, we will continue to further pursue from different fields as well as different communicative contexts.

KEYWORDS: storytelling; argumentative and persuasive texts; audiovisual advertisements.

Fecha de recepción: 14/01/2021

Fecha de aceptación: 16/02/2021

Fecha de la versión definitiva: 08/03/2021

\section{INTRODUCCIÓN}

La difusión a escala mundial del Coronavirus (COVID-19) ha impactado en nuestras vidas completamente, transformando nuestra cotidianeidad, planteándonos interrogantes y perfilando además un futuro incierto y aún difícil de divisar. Como escribe el filósofo Emilio Lledó en el artículo aparecido en El País el 29 de marzo de 2020, estamos viviendo una situación «inexperimentada porque no tenemos referentes previos, y esto nos desconcierta, pues no tenemos los automatismos emocionales para responder».

Esta emergencia sanitaria constituye uno de los retos más complejos a los que nos hemos enfrentado como sociedad en las últimas décadas, por lo que está generando incertidumbre y miedo, cuyos efectos repercuten en todos los ámbitos. Los confinamientos, establecidos en gran parte de Europa a lo largo del mes de marzo de 2020, han tenido repercusiones desde el punto de vista económico, social y, desde luego, comunicativo. Ante esta situación han cambiado las modalidades de comunicación y los propios contenidos. Y han cambiado a nivel institucional y político, así como también en otras esferas, en las que se producen mensajes que generan conexión con el público y le brindan protagonismo, puesto que la actuación individual tiene un impacto general muy fuerte. Por eso, se repiten expresiones como «esfuerzo colectivo», «colaboración», «compromiso» y «juntos», que apuntan a la «agentividad» (Duranti 2001: 268), entendida como la capacidad de producir acciones que tienen efectos y consecuencias en otros individuos o en sí mismos y que pueden someterse a valoración.

Además, en un momento de vulnerabilidad emocional es necesario mostrar solidaridad y empatía, construir mensajes positivos desde ámbitos diversos. En este sentido, lo interesante es que los argumentos empáticos, las peticiones de compromiso y las expresiones que apuntan a la «agentividad» no se limitan a la publicidad institucional, sino que alcanzan incluso 
el discurso publicitario comercial, que construye sus argumentos persuasivos en torno a estos mismos ejes pragmáticos, emocionales y axiológicos. Esto es así porque el lenguaje publicitario comercial es fundamentalmente interactivo y está necesariamente encuadrado en el entorno social en el que actúa (López Eire 2003). Como explica Leandro Raposo (Bankinter), al miedo, económico y social, generado por esta crisis se le añade «un elemento racional, más atávico, que es el de juntarnos, ya que hemos perdido la libertad de salir a la calle, y eso hace que todo sea más emocional».

Todas las marcas se han visto afectadas de una manera u otra: algunas se han visto obligadas a cerrar sus puertas y otras a reducir o restringir su actividad. Es un momento en el que los estilos de vida de todos cambian y, si las marcas manifiestan su compromiso hacia la audiencia, mostrando además ser flexibles, humanas y capaces de acercarse a su público, su acción repercute positivamente en su propia imagen. Así lo confirma un estudio publicado en el mes de abril de 2020 en la revista La Publicidad, en el que se presentan los resultados de una encuesta a los consumidores, quienes afirman, con un porcentaje que supera el $80 \%$, que comprarán más las marcas que realicen acciones solidarias contra la COVID-19. Además, el $75 \%$ de la población encuestada declara que las acciones relacionadas con paliar la crisis, realizadas por la marca, impactan positivamente en su imagen. Estas acciones son, por orden de repercusión:

1) hacer donaciones a las organizaciones públicas;

2) cambiar su producción o sus servicios y enfocarlos a resolver problemas directamente relacionados con el coronavirus;

3) planificar campañas y comunicaciones animando a la gente a que se quede en casa y mantenga el ánimo;

4) diseñar campañas entretenidas/divertidas para ayudar a la gente a ser optimista;

5) seguir produciendo y comunicando igual que antes para que la economía no se resienta;

6) dejar de hacer campañas de los productos que no sean de primera necesidad.

La publicidad comercial es también, ahora más que nunca, una institución social y política y, por lo tanto, contribuye a construir el discurso y la narrativa sobre la pandemia: las marcas tienen un rol crucial que desempeñar en la manera en la que entendemos y conceptualizamos esta realidad. La marca aspira a una condición existencial desde la que proponer valores, en nombre de los cuales ofrece a sus destinatarios la posibilidad de articular su propia identidad subjetiva. De ahí que las marcas no sean solamente entidades de las que adquirimos productos o servicios, sino actores sociales capaces de liderar cambios o actitudes en el público. 


\section{OBjetivos y MEtodología}

A partir de estas premisas y consideraciones generales, en el presente trabajo nos proponemos analizar un corpus de anuncios comerciales audiovisuales en español transmitidos tras la entrada en vigor del confinamiento del mes de marzo de 2020 para analizar cómo se construye la argumentación y cuáles son las estrategias persuasivas de las que se sirven las marcas comerciales.

En efecto, a nuestro modo de ver, tanto la argumentación como la persuasión puestas en marcha en dichos anuncios se enmarcan en la estrategia macrodiscursiva del storytelling (véase §3) y presentan diferencias lingüísticas relevantes con respecto a los anuncios comerciales transmitidos fuera de la emergencia sanitaria causada por la COVID-19.

La muestra se compone de 50 anuncios de marcas comerciales recogidos durante los meses marzo-diciembre 2020, que venden tanto servicios (seguros, bancos, líneas Internet y telefónicas, entre otros) como productos (cervezas, coches, alimentos, muebles, etc.). Algunos de estos servicios (telefonía) o productos (muebles, menaje de hogar) son, por la situación de confinamiento por el COVID-19, muy propensos a manejar los recursos retórico-persuasivos que se analizan en el artículo. La lista completa aparece en la tabla 1 del apéndice.

Tras la recolección y selección de los anuncios, se ha procedido a su transcripción y análisis. Para llevar a cabo este último se ha adoptado un enfoque cualitativo a partir de un estudio cuantitativo desarrollado mediante el empleo del programa de análisis semiautomático de textos AntConc.

En este trabajo se asume que los anuncios se organizan en forma de relatos y que estos constituyen expresiones discursivas que vehiculan y construyen conocimiento sobre las realidades socioculturales, políticas y naturales del mundo. Por eso, se propone un estudio pragmático y discursivo de las narraciones de marcas comerciales y se adelanta la hipótesis general de que son instancias discursivo-narrativas complejas, resultado de una serie de mecanismos articulados de significación, que proceden sobre todo de los niveles léxico-pragmático y retórico.

Dentro de un trabajo de investigación que trata de situar la narración comercial en la intersección disciplinaria entre las teorías de la narración y la lingüística, no se puede pasar por alto la convicción básica de que cualquier forma diegética consiste inevitablemente en un evento comunicativo. De acuerdo con este enfoque, es importante reiterar que toda narración se manifiesta como un acto relacional que involucra al menos a dos actores (no necesariamente copresentes) en una actuación de enunciación, que puede describirse a través de los seis componentes básicos jakobsonianos (o las posteriores revisiones y adaptaciones de este modelo de comunicación): 
el emisor, el receptor, el canal, el código, el contexto y el mensaje. Algunos estudiosos (entre ellos, Giovannetti 2012) han propuesto lecturas comparativas entre el evento comunicativo y la estructura narrativa que, a su vez, han dado lugar a una propuesta aglutinadora muy interesante y compartida por quien escribe: un esquema canónico de comunicación narrativa al que se pueden adscribir las manifestaciones discursivas (Cerutti 2019).

\section{FiguRA 1. Reelaboración propia del esquema propuesto por Cerutti (2019)}

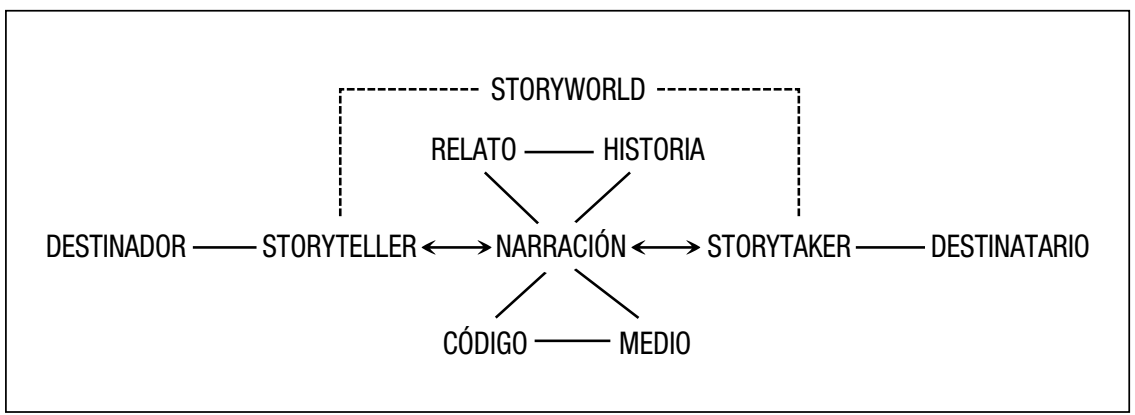

Según esta sistematización, la narración, en su naturaleza de lenguaje, se realiza mediante un medio que respeta las características del código y, en cuanto acto comunicativo, conecta a dos actores reales, el destinador (emisor) y el destinatario de la actuación discursiva ${ }^{1}$. Pero, para ser considerada narración, el relato debe transmitir también un mensaje con un componente diegético, reconocible por algunos elementos fundamentales, a saber, personajes, escenario, transformaciones de estado, secuencialidad, etc., que juntos constituyen el mundo del relato (storyworld). También forman parte de este mundo representado las dos instancias intradiegéticas de storyteller, o narrador, y storytaker, o destinatario interno de la narración.

Ahora bien, ¿por qué las marcas emplean el storytelling como recurso de persuasión? Porque las historias son fáciles de entender y recordar, además establecen un terreno común para generar un sentido de empatía desde una posición cognitiva y emocional y, por consiguiente, ayudan a entender las experiencias de otros, al igual que las visiones del mundo propio y el de los demás (Lämsä y Sintonen 2006).

\footnotetext{
${ }^{1}$ Los términos «destinador» $\mathrm{y}$ «destinatario» son las traducciones al español de los términos italianos destinante y destinatario, empleados en el ámbito de la narratología y, en concreto, en el citado trabajo de Cerutti (2019), que aquí proponemos aplicar al storytelling de los anuncios comerciales.
} 
Las historias orales (o trasmitidas a través de canales multimodales basados en el audiovisual) tienen características distintas a las escritas, debido a las especificidades del canal de expresión. Referencia seminal a este respecto es la obra de Ong (1982), según quien la dimensión oral presenta las siguientes características:

a) considera la palabra como dotada de poder y acción;

b) construye el discurso bajo matices antagónicos (rivalidad y lucha);

c) emplea estrategias para favorecer una identificación comunitaria, empática y participativa;

d) y es de carácter situacional antes que abstracto.

Como se verá, muchas de ellas se aplican también a la descripción de los datos que forman parte de nuestro corpus. De ahí que podamos afirmar que el storytelling audiovisual se presenta como una historia multimodal, en la que se establece una conexión emocional entre destinador y destinatario, lo cual permite que el mensaje perdure durante más tiempo y produzca un cambio de conducta en el destinatario, debido a que este último ha sido parte activa en el mensaje (como evidencia la flecha bidireccional en el esquema de la figura 1). De hecho, los efectos de la narración se producen gracias a la implicación de los destinatarios, algo que se logra tanto a través del «uso» de las emociones (alegría, tristeza, desilusión, miedo, etc.) como mediante la «agentividad», esto es, dirigiéndose al destinatario como comprometido y corresponsable de las acciones narrativas.

\section{ARGUMENTACIÓN Y PERSUASIÓN EN LA PUBLICIDAD: EL STORYTELLING}

«La publicidad es un tipo de discurso con una finalidad clara e inequívoca: persuadir al destinatario para que adquiera un producto, servicio o -en un plano más ideológico que comercial- sea fiel a una marca, se adhiera a una idea o la asuma» (Hernández Toribio y Mariottini 2020a: 196). La publicidad intenta suscitar una reacción en el receptor, que puede ser tanto el posterior acto perlocutivo extradiscursivo de compra como la transformación de valores sociales y de pautas de comportamiento vigentes.

Por otra parte, la publicidad es un discurso semiológicamente mixto (Kerbrat-Orecchioni 1998), un género aglutinador de distintos lenguajes (Gutiérrez Ordóñez 2000), que se sirve tanto de diferentes recursos, verbales, icónicos, musicales, etc., como de muy diversos soportes de comunicación, televisivos, gráficos, radiofónicos, multimedia, para perseguir su finalidad perlocutiva, es decir, seducir las voluntades e influir en los valores sociales de nuestro tiempo (López Eire 2003), y lo hace por medio de la argumentación (Perelman y Olbrechts-Tyteca 1989; Plantin y Tusón 1996): 
«un proceso discursivo por el cual el hablante ofrece una serie de enunciados como buenas razones para que su interlocutor cree $u$ opine de una manera y no de otra, u obre en una dirección concreta» (Fuentes y Alcaide 2007: 9-10).

Por lo tanto, el mensaje publicitario refleja, pero también transforma y modifica, los patrones de consumo y el estilo de vida de los consumidores; crea y recrea historias para convencer; estimula el deseo hacia un producto; contiene agresividad, pero también humor, simpatía, etc.; apela a los sentimientos más profundos del consumidor; y, finalmente, integra un ritmo, una cadencia, una estética, unos valores (Rodríguez García 2008). Todo ello para asegurar su objetivo: la venta del producto o servicio, así como también la adhesión a la imagen de la marca. Para conseguirlo, la publicidad seduce, fascina, busca diferentes modos sutiles, pero efectivos, de persuasión, en concreto, los argumentos lógicos, emocionales o éticos.

Los argumentos lógicos o racionales son aquellos que se basan en deducciones, inducciones e informaciones para convencer de las ventajas del producto. Los argumentos emocionales o afectivos son los que se basan en el estado de ánimo del receptor, apelan a sus sentimientos (anhelos, temores, etc.) o intentan provocar otros nuevos (el placer de lo prohibido, la sensación de necesidad, etc.). Los éticos son los que proceden de una autoridad reconocida e intentan influir en las creencias, las actitudes y la conducta del destinatario mediante la transmisión de un mensaje orientado a la objetividad, la exactitud y la verdad, ante el que, además, el destinatario mantiene su libertad de elección (Martín Salgado 2002).

Sin embargo, es preciso cuestionarse sobre quién puede producir argumentos de autoridad y bajo qué condiciones.

A este interrogante, responden los autores del llamado "giro performativo» en lingüística, quienes, desde los años 50 del siglo pasado, se han interesado en la forma en que las palabras no solo son capaces de comunicar, sino también de consumar acciones. Entre los autores que han explorado la performatividad del lenguaje, Austin y Bourdieu son, sin duda, los referentes teóricos fundamentales para examinar «la eficacia simbólica» de las historias que funcionan como «discursos de autoridad». Pionero de las teorías performativas, Austin (1962) trabajó en la teoría de los actos del habla, que retomaría más tarde Bourdieu (1982) para afirmar que los discursos de autoridad tienen que ser producidos por una entidad reconocida, y este reconocimiento solo se produce bajo ciertas condiciones externas al discurso en sí, es decir, bajo ciertas circunstancias sociales.

De ahí que la persona, marca o institución reconocida como alguien que ejerce un liderazgo social, se exprese también mediante argumentos éticos que apuntan al bien colectivo. Y en la publicidad post-confinamiento abundan los argumentos éticos, acompañados de los emocionales. Las empresas 
se esfuerzan en diseñar un contenido empático y ético a la vez, entendible para todos, que aborde las preocupaciones de la sociedad, recomiende acciones responsables mediante campañas divertidas o entretenidas. Por eso acuden a la técnica del storytelling: "el arte de inventar y contar historias» (Lamarre 2019), que, trasladado al discurso publicitario, consiste en transmitir un mensaje en forma de relato con el propósito de conectar emocionalmente con el destinatario e influir en él y en su comportamiento.

El storytelling es la técnica macrodiscursiva adecuada para encuadrar los anuncios durante-la-COVID-19, puesto que todos los anuncios que componen la muestra parten de un leitmotiv o elemento cohesionador de la historia: el comienzo de la emergencia, que representa un cambio de escenario abrupto, puesto que se pasa en pocos días de llevar una vida basada en rutinas compartidas a estar confinados en casa, sin situaciones intermedias o fases progresivas en cuanto a restricciones. Por eso, este hecho puede considerarse el «nudo» de la historia. El virus se describe como el adversario, el enemigo común contra el que hay que luchar. De este modo, los destinatarios se convierten en héroes contemporáneos capaces de cumplir la misión de salvar el planeta ayudados por la marca que les ofrece su apoyo y protección. Las fases y los componentes de la historia pueden aparecer de forma más o menos explícita, como muestran los ejemplos (1) y (2). En (1) emerge el armazón narrativo, que consta de tres etapas:

1) el escenario (se describen los días y los personajes);

2) la acción (la batalla sin tregua);

3) el final y remate de la historia (la luz al final del túnel está cada día más cerca. Juntos lo conseguiremos).

En (2), escenario, acción y final son implícitos en las selecciones léxicas del mensaje: en efecto, el verbo «volver» presupone la existencia de un estado previo que parece haberse interrumpido, pero que se pretende recuperar.

(1) Están siendo días complicados, días de sacrificio, solidaridad, entrega y dedicación. Días en los que nuestras vidas y costumbres más sencillas también se han visto alteradas. En Palacios siempre hemos dicho que somos el secreto de una familia y en circunstancias tan difíciles como las actuales sabemos que el secreto de una familia es permanecer unida y ayudarnos los unos a los otros. Por eso en Palacios queremos sumarnos a este propósito: facilitando alimentos a los voluntarios y personal sanitario de Ifema en Madrid, proporcionando mascarillas a los bomberos en Logroño, batas para el hospital San Pedro de La Rioja, mascarillas y guantes para el Ayto. de Sant Quirze del Vallès en Barcelona, protectores para el Centro de Salud de Nájera en La Rioja y todo aquello que ya estamos proyectando por el bien común para las próximas semanas. En una batalla 
sin tregua con todas las empresas del sector y sus trabajadores, dando el máximo sin excepción. Los competidores pasando a ser colaboradores, trabajando codo con codo, todos a una, porque estos días somos una familia de millones de personas y ese pequeño gran secreto nos hace inseparables e invencibles, convencidos de que juntos lo vamos a conseguir, convencidos de que la luz al final del túnel está cada día más cerca. Palacios, el secreto de una gran familia, juntos lo conseguiremos \#juntosloconseguiremos. (Palacios)

(2) Un día menos para volver con más ganas que nunca. (Decathlon)

Por eso, podemos afirmar que los anuncios audiovisuales transmitidos tras la entrada en vigor del confinamiento tienden a construir su argumentación mediante el empleo de historias de valor que narran el presente, partiendo del pasado, y se dirigen hacia un futuro para cuya realización se implica al destinatario de forma directa. Podemos afirmar, retomando las observaciones de Briz (2016: 49) sobre relatos naturales, que las historias son una «estrategia que refuerza el carácter interpersonal, en tanto aumentan la solidaridad, las relaciones y los lazos entre los actores» y que, por eso, desempeñan una «función social», puesto que realzan la imagen grupal al tiempo que refuerzan la imagen positiva del destinador. La narración, por otra parte, está también al servicio de la argumentación (Briz 2016; Van Dijk 1983), puesto que las historias «se explican como soporte de una conclusión», esto es, la narración actúa «como refuerzo y elemento de validación de los argumentos o de las actuaciones de los narradores y hablantes o de algunos de sus protagonistas» (Briz 2016: 54).

En el apartado siguiente ahondaremos en el análisis lingüístico, pragmático y retórico, destacando los recursos mediante los cuales se construyen las narraciones de los anuncios comerciales recogidos.

\section{ANÁlisis DE DATOS}

\subsection{Los personajes: destinador y destinatario y la construcción pragmático-narrativa de su relación}

Partiendo del esquema propuesto en la figura 1, los actores del evento comunicativo-narrativo son el destinador (o emisor) y el destinatario. El primero es la marca, que se configura bien como garante de un universo de valores o bien como entidad que manipula al otro actor, destinatariohéroe para que cumpla la acción resolutiva de la situación. Entre ellos no se establecer un acuerdo igualitario, puesto que el destinador, mediante argumentos de autoridad, dirige y orienta las acciones del destinatario. Sin embargo, los dos comparten intereses y objetivos, y proporcionan a la causa 
de la narración un espacio compartido: un storyworld para habitar juntos, en el que construir la conexión y consolidar una relación basada en la confianza mutua y en acciones correlativas. Este storyworld se explicita mediante recursos léxicos y, en primer lugar, mediante el empleo del término «juntos» que se repite en el corpus 18 veces.

(3) Juntos ganaremos esta batalla. (Estrella Galicia)

(4) Juntos lo conseguiremos. (Santalucía Seguros)

(5) Juntos para ayudarte. (Carrefour)

Las relaciones entre los personajes, según la narratología, se basan en tres patrones básicos: el deseo, la comunicación y la participación. En el caso que nos ocupa, nos encontramos ante el tercero de los patrones mencionados, la participación, a través de la que se pone en marcha la construcción de la comunión y unión ante el desconcierto creado por la transformación del estado inicial. En efecto, a la incertidumbre, al miedo y a la inseguridad provocados por la situación desencadenante se responde colectivamente, evocando la «unidad» sea mediante el término «juntos» (como en 3, 4 y 5) sea mediante el nosotros incluyente, como en (6):

(6) ... Cuanto más aumentan las barreras, más crece el ingenio para derribarlas. Por cada noticia que nos da miedo nace un nuevo valiente. Por cada puerta que se cierra, se abren miles de ventanas. Por cada metro que nos aleja, la empatía más nos acerca. Por cada virus hay una vacuna de positividad. Porque no hay nada más contagioso que el optimismo y aunque hay cosas que nos separan, encontramos la manera de permanecer unidos. A nuestra familia, a todos los niños, a todos los héroes de la humanidad, gracias a todos por ver el vaso medio lleno. (Coca-cola)

$\mathrm{Al}$ igual que el nosotros incluyente, la marca de segunda persona también es una estrategia léxico-pragmática empleada con el propósito de construir cercanía y comunión entre los actores. Este recurso activa, asimismo, funciones comunicativas encaminadas a la persuasión hacia la adhesión a la causa social (Serrano y Hernández Toribio 2015) por el bien de todos. De ahí que el destinatario resulte ser en todo momento el responsable de sus acciones, cuyos efectos y consecuencias se reflejan en la comunidad entera. Así, se puede observar explícitamente en algunos mensajes:

(7) Porque eres responsable y solidario, estás siempre al pie del cañón. (Florette)

(8) Cuando te encuentres con tu padre, madre, abuelo, tía no te sientas culpable por no abrazar ni besar. Es la mejor muestra de afecto que les puedes dar. ¡Con prudencia avanzamos seguros! (12.Meses Mediaset España) 
(9) Cuando te vayas a la cama, pon a cargar tu móvil y abre la app DreamLab de Fundación Vodafone. La potencia del microprocesador de tu teléfono ayudará a acelerar la investigación contra el COVID-19, que está llevando a cabo la Universidad Imperial College of London. Juntos, podemos ayudar en la lucha contra el COVID-19. (Vodafone)

Otro término que incide en los actores de la narración, y que remite a la participación, es «familia» en tanto que grupo que comparte la fortuna y las adversidades, y lugar seguro donde refugiarse.

El espacio de la familia, por lo tanto, se construye en las narraciones desde la perspectiva de los destinatarios y es un ambiente simbólico, puesto que establece una relación antitética entre dos mundos aparentemente incomunicados entre ellos: dentro-fuera, casa-fuera de casa, que remiten a las antítesis miedo-seguridad y bueno-malo. Por consiguiente, se aplica al análisis de estas historias lo que afirmaba Lotman (1985) sobre las estructuras espaciales. Parafraseando al estudioso ruso, la lengua de las relaciones de espacio es uno de los elementos centrales para comprender la realidad: los conceptos dentro-fuera, abierto-cerrado, son materiales que sirven para la construcción de modelos culturales que van mucho más allá de los elementos espaciales que vehiculan. En nuestro caso, la «frontera» entre interno y externo a la que alude Lotman sirve para presentar el «cuadro del mundo»: el espacio interno es el refugio seguro, mientras que el espacio externo es el del caos, del desorden, de la inseguridad y, sobre todo, de la oposición al bien común.

(10) Gracias a la familia aprendemos a valorar todo lo que tenemos. El Pozo nació y creció por la ilusión y el esfuerzo de una familia. Por eso, sabemos que lo importante es estar unidos siempre. Estamos a tu lado trabajando para todo lo que necesites, en estos momentos tenemos que ser una gran familia para que pronto volvamos a disfrutar juntos. Quédate en casa por ti y por todos y ahora más que nunca recuerda que una familia unida... ya sabes. El pozo uno más de la familia. (El Pozo)

La familia puede evocarse de forma directa, mediante el empleo y reiteración del propio término, como ocurre en (10), o indirecta, como en (11), en que niños pequeños (storytellers) se dirigen a los abuelos y yayos (storytakers) que no pueden ver para mandarles un abrazo grande. En este caso, la historia del anuncio apunta también a las emociones compartidas: la tristeza de no poder ver a los mayores y el deseo de volver a encontrarlos y abrazarlos. Los personajes representados son reales o verosímiles y lo que sienten no es ficción ni resulta forzado, por eso el relato consigue que el destinatario se identifique con los sentimientos de los personajes de la narración. 
(11) Hola abuela, te echo de menos. Hola, abuelo. Yayo. Necesito un abrazo yayo. Un abrazo así. Así te voy a estrujar. Uno grande, abracito. Hasta la luna y vuelta. Ay mis nietas [imitando]. Un achuchón gigante a la abi. Darle un achuchoncillo. Todo el día. Hasta Japón. Mientras llega el abrazaco, regístrate en Dodot VIP y por la compra de un pack de Dodot, te enviamos a casa otro gratis. Un abrazo muy grande. (Dodot)

Para crear conexión entre los héroes de la historia, no se emplean solo recursos léxicos, sino también estrategias pragmáticas, que se ponen al servicio del relato y de la relación entre sus personajes: es el caso de los actos de habla expresivos y, entre ellos, los cumplidos y agradecimientos, sobre todo. De hecho, "los actos de habla expresivos se convierten en extraordinarias estrategias al servicio de la persuasión emocional, ya que mediante ellos se busca desencadenar en el consumidor emociones y sentimientos positivos» (Hernández Toribio y Mariottini 2020b: 54).

(12) A nuestra familia, a todos los niños, a todos los héroes de la humanidad, gracias a todos por ver el vaso medio lleno. (Coca-cola)

(13) Para que no pare el mundo, a todos vosotros gracias por demostrar que somos capaces de movernos sin movernos. (Škoda)

(14) Gracias valientes. (Atresmedia - Patatas Hijolusa)

Los agradecimientos, en los casos analizados, se caracterizan por ser actos que lleva a cabo el hablante basándose en una acción presente o futura del destinatario, que va a resultar beneficiosa para ambos. Por eso, son actos de convivencia y de gran valor social (Leech 1983), puesto que establecen cordialidad entre los interlocutores y evocan propósitos comunes y compartidos.

Los actos expresivos acompañan a menudo otro de los elementos típicos del storytelling: la trasformación del héroe. Esto es, en las historias, el héroe evoluciona, cambia a lo largo del relato y lo hace a través de sus acciones, que contribuyen a construir su yo final, como muestra el ejemplo (15), en el que se enumeran las proezas del héroe y de la heroína antes del cierre del telón ( $p$ por eso este aplauso va por ti»):

(15) En los momentos más difíciles es donde se muestra el verdadero valor. Y estos días, con tu compromiso, lo estás demostrando. Tú eres un héroe. Tú eres una heroína. Y por ello, queremos decirte que estamos orgullosos de ti \#orgullososdeti. Orgullosos por muchas razones:

1. Porque has logrado que sigamos adelante dando de comer a millones de familias.

2. Porque tú nos haces un equipo, organizas, transportas y haces que nada falte en tu tienda. 
3. Porque ayudas a personas que están luchando en primera línea dando miles de ensaladas, donando mascarillas, guantes y equipos de protección.

4. Porque eres responsable y solidario, estás siempre al pie del cañón.

Orgullosos de ti porque incluso en las circunstancias más difíciles, ayudas a las personas a alimentarse mejor.

Por eso este aplauso va por ti. (Florette)

El ejemplo (15) muestra también que los cumplidos pueden aparecer, como indica Hernández Toribio (2016), bien como actos directos bien como encubiertos, generalizadores y a través de terceros. Siguiendo a las definiciones que brinda esta autora, los macroactos expresivos más empleados en nuestro corpus son los directos -que hacen referencia explícitamente al destinatario o a las cualidades objeto de la valoración (ej. "gracias valientes»)- y los implícitos a través de terceros -que, en los casos que aquí analizamos, son los storytakers (ej. «orgullosos de ti» donde cada «ti» se refiere a una categoría distinta, representada en las imágenes narrativas: tenderos, camioneros, enfermeros, voluntarios, etc.)-, que representan estereotípicamente al público destinatario y con los que se espera que este se identifique.

Los cumplidos y agradecimientos que aquí se emplean, además, son actividades de autoimagen (Hernández Flores 2005, 2013), que resultan beneficiosas para la imagen de la marca, puesto que esta se muestra como un actor social responsable, colaborador y concienciador.

Podemos afirmar, en definitiva, que el destinador es responsable de la voluntad, del sistema moral, comunicado mediante un código multimodal, y el destinatario es responsable del deber relativo a la acción a realizar. Desde este punto de vista, abordar el storytelling en su naturaleza de lenguaje tiene el mérito de labrar un papel decisivo para el destinatario dentro de la teoría narrativa, y de atribuirle una posición que no es secundaria en la dinámica del discurso narrativo.

\section{$4.2 E l$ storyworld}

\subsubsection{Tiempo y espacio de la narración}

Los recursos léxicos son importantes también porque, además de construir la relación entre los actores de la narración, contribuyen a montar la estructura temporal de la historia.

Sabemos que en el modelo narrativo clásico hay comienzos que marcan los momentos tópicos en los que la situación inicial sufre un cambio radical y repentino, a partir del cual los personajes deberán tomar decisiones y realizar acciones para poder salir. Estos comienzos son: «érase una vez...», «cada día...», «pero un día...», «por eso...», «hasta que al final...». 
También, en el caso que nos ocupa, es posible divisar la misma estructura en fases. Abundan los términos que remiten a un escenario precedente, a una situación anterior, caracterizada por acciones habituales que, de repente, se han visto interrumpidas: se construyen frases contrapuestas «siempre..., pero esta vez...» y comparativas «ahora más que nunca»:

(16) Hay muchas cosas que nos unen, como el esfuerzo de las personas que trabajan tanto para superar esta situación excepcional. Por eso, ahora más que nunca, estamos con los autónomos y sus negocios, con las PYMES y las empresas para que sigan adelante y mantener el empleo, para volver a la normalidad porque todos queremos volver a trabajar, a crecer, a progresar, a viajar. Y en el Santander aquí estamos, juntos vamos a conseguirlo. Santander, el banco de todas las empresas. (Banco Santander)

(17) Siempre hemos estado cerca para que estés seguro. Pero ahora lo importante es no estar tan cerca para volver a estar seguros. Separarnos para volver a estar juntos, distanciarnos para volver a acercarnos, estar ausentes para volver a estar presentes. Estar lejos para volver a estar más cerca. Por eso, siempre que puedas, quédate en casa y pronto volveremos a estar cerca, juntos lo conseguiremos. Santalucía Seguros. Ahora no hay que estar cerca, para que estés seguro. (Santalucía Seguros)

(18) «Cerrado hasta nuevo aviso por Coronavirus». Siempre hemos necesitado a los bares. Pero esta vez, ellos nos van a necesitar a nosotros. Porque siempre habéis estado ahí y volveréis a estar. Volveremos a ir a vuestra barra, a vuestra luz, a vuestras mesas, a vuestras cañas. Volveremos a ir a abrazarnos, tocarnos, a sentirnos. Escuchadnos bien: volveremos. No sé si mañana, pasado o cuando sea. Pero volveremos. Al final resulta que estar en nuestro bar, con nuestra gente, es estar en casa. Aunque esto ya lo sabíamos. Ahora, más que nunca, en Mahou trabajamos para volver a encontrarnos en nuestros bares. Ahora más que nunca, juntos para siempre. (Mahou)

La fase de decisión y acción resolutiva del nudo narrativo sobre coronavirus, en cambio, se expresa mediante un acto directivo explícito: «Por eso, quédate en casa», que se presenta como una acción que dinamiza el relato, una «bisagra proairética» (Marchese 1983), puesto que es el plan inicial del proceso con el que se pretende alcanzar el logro final.

La dinámica narrativa depende tanto de los esquemas temporales presentados arriba como de los espaciales, que permiten la expresión de la organización lógico-secuencial de las acciones.

En efecto, las narraciones que analizamos permiten leer la transformación de los personajes mediante el espacio que ocupan:

- el espacio tópico, que es el de la casa o el de la familia, en el que se cumple la batalla y la transformación de los personajes y de la situación;

- y el espacio utópico, o deseado, el externo, al que todos queremos volver. 
(19) Mientras nosotros cuidamos de tus cosas, queremos que nos hagas una promesa: que cuidarás de ti y de los tuyos. Todo volverá a la normalidad. Hasta entonces quédate en casa. Grupo Mutua Madrileña. Este virus lo paramos unidos. (Mutua Madrileña)

(20) Hoy, más que nunca, nos toca mirar la carretera hacia adelante sin poder disfrutarla como nos gustaría. Por favor, quédate en casa. (BMW)

Los relatos se construyen alrededor de esta fenomenología espacial de origen greimasiana, que además vehicula valores axiológicos y emotivos. De hecho, a la descripción de los espacios se acompañan palabras clave que se dirigen a las emociones, las que duelen, las que quieren que memorice la audiencia, las que producen miedo (de Santiago Guervós 2005). Se trata de penetrar en las percepciones de la audiencia para provocarle determinadas reacciones. La idea es simple: ayudar a las personas a superar sus temores y dificultades y conectarlas con las demás porque

(21) Cuando estamos conectados somos capaces de hacer cosas increíbles. \#seguimos conectados. (Movistar)

Esto confirma lo que asevera Lamarre (2019: 139) a propósito del storytelling, es decir, que «los héroes de la historia funcionan en red. Ninguno existe más que en la acción y la relación que establece con los demás personajes».

\subsubsection{El escenario narrativo}

Los recursos que más se emplean para construir el escenario y posicionar a los actores son los retóricos y, entre ellos, especialmente la metáfora.

La metáfora que más se repite es la bélica, que es la misma en torno a la que se construye también el discurso político e institucional sobre la COVID-19 (véase a este respecto Olza 2020; Filardo-Llamas 2020).

(22) ... En una batalla sin tregua con todas las empresas del sector y sus trabajadores, dando el máximo sin excepción. (Palacios)

(23) Puede que nuestras calles nunca hayan estado más vacías. Sin embargo, nunca hemos luchado más unidos. Unidos como un gran País, solidario, valiente y con el sentido del humor que nos define hemos ganado ya muchas batallas. Y esta también la ganaremos juntos. (Atresmedia)

(24) Juntos, podemos ayudar en la lucha contra el COVID-19. (Vodafone)

(25) ... Cada acción cuenta, prevenir el contagio depende de nosotros, porque esta lucha es de todos. (12.Meses Mediaset España) 
(26) Resistiremos en cada casa, resistiremos en cada balcón, resistiremos en cada terraza y en cada ventana. Resistiremos con elegancia, resistiremos en chándal y hasta en albornoz. Resistiremos aplaudiendo, resistiremos bailando y haciendo bailar, resistiremos en cada pasillo y en cada metro de parqué. Resistiremos trabajando para volver más fuertes, más unidos y más guapos que nunca. Juntos ganaremos esta batalla, porque juntos somos y seremos la resistencia. \#yoresistoencasa. (Estrella Galicia)

El escenario, por consiguiente, asume la forma hostil, puesto que los protagonistas quieren derrotar al adversario mediante una agresión, una batalla. Esto tiene consecuencias narrativas importantes, porque, por un lado, comporta un peligro y, por otro, la adopción de una actitud protectora.

Las modalidades con las que se construye el escenario pueden ser múltiples y distintas: la palabra suele alternarse con recursos tales como la música, la imagen estática o en movimiento, los efectos visuales o sonoros, el paralenguaje, el silencio, etc., en función de las peculiaridades establecidas por el soporte empleado (Hernández Toribio 2006: 224). En el último ejemplo presentado (26), donde se habla de «resistencia» para ganar la batalla, se emplea la música y la banda sonora es la canción Bella Ciao, conocida en todo el mundo como canto de resistencia y libertad.

La música puede desempeñar una función central para incrementar los niveles de recuerdo y de reconocimiento de los demás elementos, verbales y visuales, puesto que el ambiente que se «respira» en una escena depende del conjunto de factores que la componen: espacio, tiempo, personajes, interacción y, cómo no, sonido. Gracias al carácter multimodal del anuncio, se pueden crear metáforas y narraciones auditivas que, por sí mismas, tienen una gran fuerza comunicativa y dominan la (des)codificación de la situación. Otro ejemplo es el anuncio de Bankinter (en apéndice el enlace).

Como ya señalaron Lakoff y Johnson (1986), la metáfora, lejos de ser exclusivamente un hecho lingüístico y discursivo, tiene efectos también en el pensamiento y la acción. Dicho de otra forma, no se trata simplemente de un modo de hablar, puesto que las metáforas estructuran la manera en que percibimos, pensamos y actuamos. Por lo tanto, si hablamos de «batalla» y de «resistencia», pensaremos y actuaremos en consecuencia: planificaremos, usaremos estrategias, atacaremos, resistiremos, etc., es decir, viviremos conforme a ese esquema conceptual. De ahí que, por ejemplo, «se hagan reservas» para afrontar los días de encierro y aislamiento.

... La crisis del Coronavirus sigue afectando al mundo. La mayor crisis colectiva de esta generación. Las cifras de contagios ya son muy preocupantes. Calles prácticamente vacías y los comercios cerrados. Colas interminables, estantes vacíos y carros a rebosar... (Florette) 
A veces, las batallas son épicas, por eso se remite al «héroe» y a la «heroína», y a su valentía, sacrificio y esfuerzo. El héroe es un personaje que enlaza con el concepto de mito y con una forma de relato superior, como evidencia Salmon (2008), por eso es un modelo de comportamiento no ya de lo que debe ser, sino de lo que debería ser.

(28) Héroe - Heroína: persona que se distingue por hacer una hazaña extraordinaria que requiere mucho valor y que es admirada por todos. [...] En los momentos más difíciles es donde se muestra el verdadero valor. Y estos días, con tu compromiso, lo estás demostrando. Tú eres un héroe. Tú eres una heroína... (Florette)

(29) Eres un héroe por trabajar desde casa, por hacer los deberes todos los días, por cocinar para ti sola, por cuidar de todos, por tocar la guitarra para ti y para todo el barrio. Hoy más que nunca nos hemos convertido en auténticos héroes. (MAPFRE)

La batalla, sea esta cotidiana o épica, abre la posibilidad de incluir, dentro del storytelling, un personaje ayudante del protagonista que, en este caso, sería la marca, cuya función es la de apoyar al héroe o heroína para que cumpla su misión: cuidar de los suyos, de la casa, llevar adelante el trabajo, compaginarlo todo, etc.

(30) Llevamos años trabajando para que puedas hacerlo todo en cualquier sitio. Y ahora que toca hacerlo desde aquí o aquí queremos, más que nunca, estar contigo y ayudarte. (BBVA)

(31) Contigo, que estás preocupada.

Contigo, que ahora estas más con ellos.

Contigo, que no deberías sentirte solo.

Contigo, que no te vas a rendir nunca.

En CaixaBank estamos contigo más que nunca.

\#Contigomasquenunca (CaixaBank)

Sin embargo, la metáfora de la batalla no es la única presente en los anuncios analizados. Otras son:

- la oscuridad: el tiempo durante la COVID-19 es un tiempo oscuro y, cuando acabe, volveremos a la luz.

(32) ... convencidos de que juntos lo vamos a conseguir, convencidos de que la luz al final del túnel está cada día más cerca. (Palacios)

(33) Donde nos llevó la imaginación, donde con los ojos cerrados se divisan infinitos campos. Donde se creó la primera luz junto a la semilla del cielo azul... (Atresmedia) 
- el movimiento: la situación de emergencia sanitaria supone un parón del mundo; la salida de la emergencia una vuelta al movimiento, y el connotado positivamente va hacia adelante, «avanza»:

(34) Cuando pensábamos en movernos, pensábamos en salir de casa, ir de un sitio a otro, recorrer cientos de kilómetros hasta que un día tuvimos que parar y al parar descubrimos que aún sin poder salir de casa somos capaces de movernos para que no pare nada.

Para que no paren las galas, las fiestas, las risas, la piel de gallina, los proyectos, los sueños, los mensajes que dicen tú puedes y los que dicen gracias.

Para que no paren los bailes, los conciertos, la magia para que no pare la vida.

Para que no pare el mundo, a todos vosotros gracias por demostrar que somos capaces de movernos sin movernos. Muévete siempre. (Škoda)

(35) Espacios vacíos, ¿Para qué estamos viviendo? Lugares abandonados... supongo que todos sabemos lo que pasa. Continuamente ¿Acaso alguien sabe lo que estamos buscando? Otro héroe, otro crimen sin sentido. Detrás de la cortina, en el teatro, mantén la línea ¿Acaso alguien quiere soportarlo más? Un gran país empieza a ponerse en marcha. Y su televisión también. Atresmedia la televisión de un gran país. (Atresmedia)

(36) Ahora que ya hemos arrancado es hora de avanzar y para que nadie se quede atrás llega el compromiso Hyundai. (Hyundai)

Además de las metáforas, hay otros mecanismos retóricos al servicio de la narración, como es el caso de la personificación. La casa, el lexema más empleado (se repite 28 veces y se encuentra en la posición 23 de la lista de frecuencia), y el lugar al que más se remite, adquiere rasgos humanos y le habla a su habitante:

(37) Hola, soy tu casa, soy tu hogar. Sigo siendo el espacio donde han crecido tus hijos, donde has celebrado las buenas noticias y te has refugiado de las malas. Soy el lugar donde eres tú mismo, ¿te acuerdas de cuando nos conocimos? Venga, va. Siénteme. Huéleme. Disfrútame. ¡Podemos poner todo del revés! Quizás este es el momento de mover los muebles o de amueblarnos la cabeza. Yo soy tu hogar y voy a estar para ti, aguantando todo lo que venga. Yo me quedo en casa \#yomequedoencasa. (Ikea)

El ejemplo (37) es muy interesante también porque la historia que presenta es muy cercana al público que la recibe y transmite la idea de que este, renovando su hogar, puede renovar su vida. La empresa, por lo tanto, ofrece una promesa de futuro, dando la posibilidad de convertir la casa en un hogar, en nuestro territorio, consiguiendo que el destinatario perciba la marca como una forma de mejorar su vida, de sentirse apoyado y seguro en su propio hogar. 
Finalmente, encontramos recursos retóricos empleados para «amplificar el argumento verbal en la misma dimensión de la elocución del mensaje donde se registran las recurrencias» (López Eire 2003: 80), entre ellos

- la diáfora:

(38) En BMW, tomar una curva esta en nuestro ADN. Pero ahora, debemos enfrentarnos a una curva como nunca antes habíamos visto. Lo más importante es estar seguros de que nos enfrentamos a ella de la mejor manera posible. Así que, hagamos lo posible, todos, para reducir esta curva. Hoy, más que nunca, nos toca mirar la carretera hacia adelante sin poder disfrutarla como nos gustaría. Por favor, quédate en casa \#quédateencasa. (BMW)

(39) A la derecha y a la izquierda, cerradas y abiertas, sobre barro, nieve y agua, hemos dominado incluso las que parecían imposibles. Pero esta curva solo podemos dominarla todos juntos. \#quédateencasa para \#frenarlacurva. Seguimos a tu lado. (Audi)

(40) En estos tiempos difíciles hay miles de personas que se han volcado en ayudar a los demás. Profesores que siguen conectados a sus alumnos. Personas usando sus máquinas de coser para hacer mascarillas. Y miles de médicos y sanitarios cuidando de nosotros noche y día. Cada vez estamos más cerca \#quenonosfaltelaenergía. En Endesa estamos a tu lado trabajando para llevarte toda nuestra energía y que todo funcione. (Endesa)

- la antanaclasis:

(41) Seguro que teletrabajaste, limpiaste, sudaste. Seguro que cantaste, adelgazaste, dormiste, cocinaste, saludaste al sol, improvisaste. Y seguro que matchearás, besarás, descubrirás. Seguro que correrás, reirás, abrazarás, celebrarás. Seguro que viajarás seguro. Seguro con cabify. (Cabify)

- el retruécano, seguido además de las anáforas: «volveremos a»y «a vuestra».

(42) «Cerrado hasta nuevo aviso por Coronavirus». Siempre hemos necesitado a los bares. Pero esta vez, ellos nos van a necesitar a nosotros. Porque siempre habéis estado ahí y volveréis a estar. Volveremos a ir a vuestra barra, a vuestra luz, a vuestras mesas, a vuestras cañas. Volveremos a ir a abrazarnos, tocarnos, a sentirnos. Escuchadnos bien: volveremos. No sé si mañana, pasado o cuando sea. Pero volveremos. Al final resulta que estar en nuestro bar, con nuestra gente, es estar en casa. Aunque esto ya lo sabíamos. Ahora, más que nunca, en Mahou trabajamos para volver a encontrarnos en nuestros bares. Ahora más que nunca, juntos para siempre. (Mahou)

- el hashtag, un mecanismo retórico de amplificación del mensaje importado de las redes sociales, particularmente de Twitter. El hashtag se 
emplea 67 veces en el corpus analizado que, recordémoslo, es de anuncios audiovisuales, y acompaña mayormente al acto directivo \#quédate en casa, que, a su vez, aparece a menudo junto al logotipo y nombre de la marca, como muestran los ejemplos que siguen.
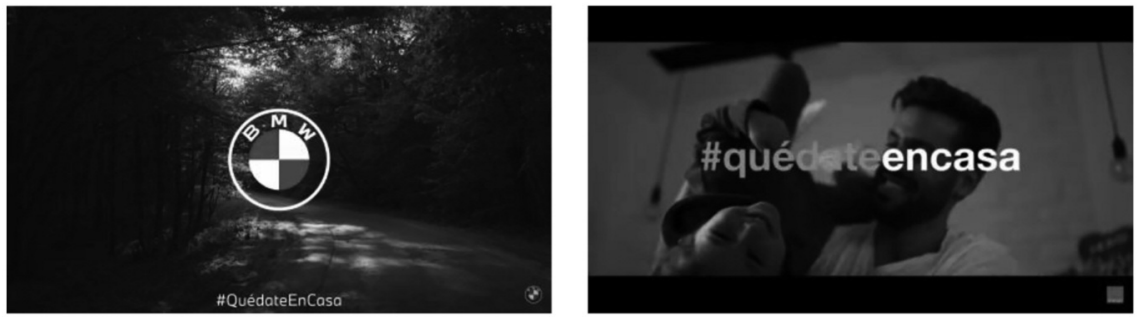

El mensaje \#quédateencasa es un lema compartido a nivel mundial en los distintos idiomas (stay at home; resta a casa, reste à la maison; etc.) y es una exhortación al destinatario para que adopte la conducta requerida, busca motivar al lector para que cumpla esta acción, puesto que es la acción que marca el desenlace de la historia.

Hay otros mensajes repetidos y vehiculados con hashtag: \#másunidos quenunca; \#juntosloconseguiremos; \#porti, \#portodos.

Los datos indican que las marcas emplean el hashtag para, en primer lugar, reproducir el discurso dominante de un momento dado y amplificar el mensaje hasta convertirlo en viral. De ahí que la primera función del hashtag en los anuncios analizados sea la indexical, puesto que depende del contexto y, del mismo modo, contribuye a construirlo.

En segundo lugar, es un instrumento con el que se pretende agrupar a todos los miembros de una comunidad en torno al mismo tema y a los valores que vehicula, de los que dicha comunidad se hace portadora.

En tercer lugar, permite indicar las intenciones de quien produce el mensaje y su nivel de compromiso; de esto se hace mención explícita en uno de los anuncios:

(43) \#Fuerzabar este no es solo un hashtag, es un compromiso por parte de Cruzcampo para dar soporte a nuestros bares. (Cruzcampo)

Finalmente, hace posible producir contenido nuevo y creativo con respecto al mensaje originario, que, además, demuestra la existencia de un trending topic (\#quedateencasa), que es la base sobre la que se construyen los demás hashtags:

(44) \#quedateencasa \#mejorateencasa \#escuchaencasa \#aprendeencasa \#leeencasa \#comparteencasa \#juegaencasa \#rieencasa \#saludaencasa \#comprendeencasa \#admiraencasa \#apoyaencasa \#felicitaencasa 


\begin{abstract}
\#perdonaencasa \#demuestraencasa \#prometeencasa \#regalaencasa \#cantaencasa \#creaencasa \#conoceencasa \#encuentraencasa \#ofrece encasa \#emprendeencasa \#respondeencasa \#sonrieencasa \#superaen casa \#muestraencasa \#reconciliaencasa \#grabaencasa \#enviaencasa \#sienteencasa \#reparteencasa \#defiendeencasa \#informateencasa \#conoceencasa \#enamoraencasa \#estudiaencasa \#leeencasa \#quedate encasa \#conectateencasa \#porti \#portodos \#porunusoLovedelatecno logia Orange Te acercamos a lo que más te importa. (Orange)
\end{abstract}

Estos ejemplos muestran la tendencia hacia la construcción de narrativas transmedia, es decir, la creación de un mundo narrativo que se expande de un medio a otro y que está formado por partes que, aunque por sí solas puedan satisfacer al destinatario, integran un todo que le da a este la oportunidad de participar de la experiencia y así sentirse parte de la misma. Por lo tanto, cabe destacar dos principales características del storytelling transmedia: por un lado, la capacidad de que la historia se extienda de un medio a otro (de Youtube a Instagram, a Facebook, a pancartas, etc.) y, por otro, la implicación del destinatario en la historia, teniendo la posibilidad de compartir la información y colaborar para construir ese mundo narrativo donde cada medio aporta una cualidad diferente (Scolari 2013).

\title{
4.3 La acción narrativa
}

Las acciones narrativas descritas en los anuncios comerciales durante la crisis de coronavirus se pueden catalogar en dos grupos: las que se refieren al presente, vehiculadas sobre todo como actos directivos, y las prolépticas, que se refieren al futuro, que se expresan mediante actos comisivos y asertivos predictivos.

Las primeras se construyen con verbos en forma imperativa y se dirigen mayormente al destinatario, a quien se refieren con la marca de segunda persona.

(45) Quédate en casa. (Audi, Mutua Madrileña)

(46) Por favor, quédate en casa. (BMW)

(47) Queremos volver a abrazarnos, a besarnos, a jugar, a bailar, a trabajar juntos. Si puedes, por favor, quédate en casa. (Banco Santander)

(48) Estar lejos para volver a estar más cerca. Por eso, siempre que puedas, quédate en casa y pronto volveremos a estar cerca, juntos lo conseguiremos. (Santalucía Seguros)

La presencia abundante de actos de habla directivos no es algo nuevo en publicidad, al contrario, coincide con la teoría en el sentido de que, en 
la mayoría de los casos, se pretende mover al destinatario a realizar una acción. Lo que sí hemos destacado como una tendencia parcialmente distinta es la construcción del acto directivo como ruego, acompañado de atenuadores de la fuerza ilocutiva, tales como "por favor», «si puedes», «siempre que puedas», o argumentos que lo justifican «estar lejos para volver a estar más cerca», que, desde la perspectiva de la pragmática sociocultural (Bravo y Briz 2004), desempeñarían las funciones autoprotectora de la imagen del emisor -esto es, la marca no es una institución y debe salvaguardar su imagen a la hora de pedir y rogar al destinatario para que se quede en casa-, preventiva o reparadora de posibles amenazas a la imagen del destinatario que estos actos directivos pueden suponer. Al hacer esto, los anuncios comerciales se acercan a los institucionales, donde los ruegos y las peticiones (atenuadas) son más comunes.

Las segundas, acciones prolépticas, se construyen en forma de actos comisivos y asertivos predictivos.

La marca ofrece una promesa de futuro mediante actos comisivos e incita a la audiencia a actuar con respecto a la salud y a la vida. Las promesas de futuro enuncian, en nuestro corpus, la intención del hablante de realizar, junto con el oyente y en beneficio de ambos, la acción descrita por el contenido proposicional.

(49) Juntos ganaremos esta batalla. (Estrella Galicia)

(50) Todo volverá a la normalidad. (Mutua Madrileña)

A veces, los comisivos se acompañan de actos asertivos predictivos que sirven para marcar la temporalidad presagiada, la ensoñación y la excursión imaginaria. Esto es, los actos asertivos predictivos desempeñan el papel de marcadores de la temporalidad narrativa que delimitan el comienzo y el final de la prolepsis. Con este recurso narrativo, se interrumpe el momento presente para anticipar una declaración o anunciar acontecimientos que tendrán lugar en el futuro.

(51) Volveremos y Manuel nos pondrá al día con sus teorías de la conspiración, siempre tan ingeniosas. Volveremos para escuchar la mejor banda sonora del mundo: «croquetas», para limpiarnos esa deliciosa salsa una y otra y otra vez para ser el ganador entre los perdedores, para luego ir al siguiente bar y empezar todo de nuevo. Volveremos. Y apreciaremos nuestros bares más que nunca. (Coca-cola)

(52) Y volverán esos momentos

de las cosas cotidianas

una cena con amigos

un beso cada mañana

de gastarlo en cosas simples

que hoy parecen muy complejas. (Bankinter) 


\section{Conclusiones}

El análisis ha demostrado la importancia y centralidad de los recursos léxicos, pragmáticos y retóricos en el storytelling publicitario de tipo comercial: las palabras contribuyen a construir el escenario, los personajes y la estructura temporal, así como también llevan una gran carga argumentativa, lo cual significa que nos «posicionan con respecto a los contenidos afirmados» (Kerbrat-Orecchioni 1986: 108), nos hacen acercar y hasta identificar con las instancias narrativas, con sus emociones y sus deseos.

La crisis sanitaria en la que se enmarcan las narraciones examinadas se ha transformado en una policrisis, puesto que afecta a todos los ámbitos de vida: sanitario, económico, social y familiar. De ahí que haya servido articular nuevas coaliciones más allá de la política o de las instituciones para afrontarla y para crear un marco que afirme nuestra vulnerabilidad radical y nuestra interdependencia (Magallón Portolés 2014); un marco que enfatice la necesidad de reforzar los lazos y vínculos entre las personas, basados en la corresponsabilidad y en la lógica del bien común. Se trata de fortalecer los discursos que apuntan a la colectividad, resiliencia y resistencia para afrontar los grandes retos que nos plantea esta situación inédita. Se trata, en definitiva, de crear una narrativa inclusiva para construir un mundo en común (Mesa y Alonso Cano 2019-2020).

Pues bien, a partir de estos propósitos, los discursos publicitarios comerciales post-confinamiento han transformado en parte sus estrategias y sus mensajes para adecuarlos al contexto específico de emergencia sanitaria y vehicular un tipo de discurso que refleja y amplifica el institucional. Y lo hacen mediante la estrategia macrodiscursiva del storytelling, es decir, construyen sus argumentos como historias de valor, reales y verosímiles, en las que las instancias narrativas (destinador y destinatario / storyteller y storytaker con el que el destinatario se identifica) luchan conjuntamente contra un enemigo común, el virus. De ahí que se activen, tanto a nivel léxico-semántico, como a nivel retórico y pragmático, marcos específicos que evocan, por un lado, la batalla (ej. lucha, resistencia, miedo, inseguridad, etc.), $y$, por otro, el compromiso hacia el desenlace de la historia (la vuelta a la normalidad), para recuperar la situación inicial, interrumpida de forma repentina y tajante.

La acción narrativa se vehicula mediante actos de habla directivos -para aquellas acciones que se dirigen al presente y describen el comienzo del plan para contrastar al adversario- y mediante actos de habla comisivos y asertivos predictivos - para las acciones prolépticas, que suponen una promesa de futuro a la vez que un compromiso y una corresponsabilidad del destinador y del destinatario.

De lo que se ha dicho, se desprende que la información lingüística que de los anuncios se extrae nos ha servido para interpretar la situación comu- 
nicativa, los roles de los actores y la relación que se establece entre ellos, y la acción narrativa en su secuencialidad. El destinador, que es la marca comercial, aparece como un actor social comprometido, es decir, como si fuera un organismo o institución que advierte, facilita, se preocupa y vigila por el cumplimiento de las normas. El destinatario es el coprotagonista, puesto que solo gracias y con él se pueden lograr cambios de conducta social y «volver a la normalidad».

En el esquema que sigue (fig. 2), que podría ser el mapa para enfocar otras descripciones de storytelling persuasivo desde una vertiente lingüística, se ubica lo expuesto con la asignación a su correspondiente recurso léxico y retórico o estrategia pragmática.

Figura 2. Recursos léxicos, retóricos y estrategias pragmáticas del storytelling persuasivo: recapitulación

\begin{tabular}{|c|c|c|c|}
\hline Funciones en la historia & Recursos y estrategias & Ejemplos descritos & $\S$ \\
\hline $\begin{array}{l}\text { Construcción } \\
\text { del escenario narrativo }\end{array}$ & Figuras retóricas & $\begin{array}{l}\text {-la metáfora } \\
\text {-la personificación } \\
\text {-la diáfora } \\
\text {-la antanaclasis } \\
\text {-el retruécano } \\
\text {-el hashtag }\end{array}$ & $\S 4.2 .2$ \\
\hline \multirow{2}{*}{$\begin{array}{l}\text { Tiempo narrado } \\
\text { y tiempo de la narración }\end{array}$} & Frases contrapuestas & -siempre..., pero esta vez & \multirow{2}{*}{$\S 4.2 .1$} \\
\hline & Frases comparativas & -ahora más que nunca & \\
\hline $\begin{array}{l}\text { El espacio narrado y el } \\
\text { espacio de la narración }\end{array}$ & Recursos léxicos & -oposición dentro/fuera & $\S 4.2 .1$ \\
\hline \multirow{2}{*}{$\begin{array}{l}\text { Construcción } \\
\text { de la relación entre } \\
\text { los personajes }\end{array}$} & $\begin{array}{l}\text { Recursos léxicos } \\
\text { y pragmáticos: uso } \\
\text { de términos relacionales } \\
\text { e incluyentes }\end{array}$ & $\begin{array}{l}\text {-juntos } \\
\text {-familia } \\
\text {-nosotros } \\
\text {-marcas de II persona }\end{array}$ & \multirow[t]{2}{*}{$\S 4.1$} \\
\hline & $\begin{array}{l}\text { Actos de habla } \\
\text { expresivos }\end{array}$ & $\begin{array}{l}\text {-agradecimientos } \\
\text {-cumplidos }\end{array}$ & \\
\hline \multirow{2}{*}{$\begin{array}{l}\text { La acción narrativa: } \\
\text {-nudo/desenlace }\end{array}$} & & & \multirow{3}{*}{$\S 4.3$} \\
\hline & $\begin{array}{l}\text { Actos de habla directivos } \\
\text { (atenuados) }\end{array}$ & $\begin{array}{l}\text {-por eso, (por favor) } \\
\text { quédate en casa }\end{array}$ & \\
\hline $\begin{array}{l}\text {-acción proléptica } \\
\text { (promesa de futuro) }\end{array}$ & $\begin{array}{l}\text { Actos de habla comisivos } \\
\text { y asertivos predictivos }\end{array}$ & $\begin{array}{l}\text {-volveremos, } \\
\text { ganaremos la batalla }\end{array}$ & \\
\hline
\end{tabular}




\section{BIBLIOGRAFÍA}

Austin, John L. (1962): How to Do Things With Words, Oxford: Oxford University Press.

Bourdieu, Pierre (1982): Ce que parler veut dire: L'économie des échanges linguistiques, París: Fayard.

Bravo, Diana y Antonio BRIz (2004): Pragmática sociocultural: estudios sobre el discurso de cortesía en español, Barcelona: Ariel.

BRIZ, Antonio (2016): «El relato coloquial: un hecho conversacional narrativo y una estrategia». En Elena Carpi, Rosa M. García Jiménez y Elena Liverani (eds.), Le forme del narrare: nel tempo e tra i generi, Volume I: Lingua, Trento: Università degli Studi di Trento, 7-60.

CERUtTI, Dario (2018-2019): Teorie e pratiche dello storytelling organizzativo. Applicabilità di modelli di comunicazione narrativa a imprese ed istituzioni: stabilizzazione metodologico-disciplinare e sviluppo operativo, Tesis doctoral de la Università del Piemonte Orientale.

Durant, Alessandro (2001): Antropologia del linguaggio, Roma: Meltemi.

Filardo-Llamas, Laura (2020): «No es lo mismo estar en guerra que remar juntos: la importancia de las metáforas sobre COVID-19». <https://theconversation. com/no-es-lo-mismo-estar-en-guerra-que-remar-juntos-la-importancia-de-lasmetaforas-sobre-covid-19-144337>.

Fuentes Rodríguez, Catalina y Esperanza AlCAIDE LARA (2007): La argumentación lingüistica y sus medios de expresión, Madrid: Arco/Libros.

Giovannetti, Paolo (2012): Il racconto: letteratura, cinema, televisione, Roma: Carocci.

GutiéRrez OrdóÑez, Salvador (2000): Comentario pragmático de textos publicitarios, Madrid: Arco/Libros.

HERNÁNDEZ FlORES, Nieves (2005): «La cortesía como búsqueda del equilibrio de la imagen social: la oscilación de la imagen en un debate televisivo». En Jorge Murillo (ed.), Actas del II Coloquio del Programa EDICE, San José: Universidad de Costa Rica, 37-52. <www.edice.org >.

- (2013): «Actividad de imagen: caracterización y tipología en la interacción comunicativa», PragSo 1/2, 176-198.

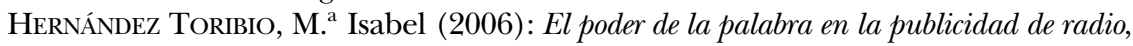
Barcelona: Octaedro.

- (2016): «Hacia una tipología del uso del acto valorativo cumplido como estrategia publicitaria», Révue Roumaine de Linguistique 2, 157-175.

- y Laura MARIotTINi (2020a): «Persuasión emocional, argumentación y publicidad». En M. Elena Placencia y Xose A. Padilla (eds.), Guía Práctica de pragmática del español, London/New York: Routledge, 196-205.

- y - (2020b): "Actos de habla expresivos y emociones en entornos digitales: publicidad en Twitter». En Luis Bagué Quílez y Susana Rodríguez Rosique (eds.), Del tópico al eslogan, Madrid: Visor Libros, 53-65. 
Kerbrat-Orecchioni, Catherine (1986): La enunciación. De la subjetividad en el lenguaje, Buenos Aires: Hachette Universidad, Edicial.

- (1998): «La argumentación en la publicidad», Escritos, Revista del Centro de Ciencias del Lenguaje 17-18, 291-326.

LAKOFF, George y Mark Johnson (1986): Metáforas de la vida cotidiana, Madrid: Cátedra.

LAMARRE, Guillaume (2019): Storytelling como estrategia de comunicación, Barcelona: Gustavo Gili.

LÄMSÄ, Anna-Maija y Teppo SINTONEN (2006): «A Narrative Approach for Organizational Learning in a Diverse Organisation», Journal of Workplace Learning $18 / 2,106-120$.

LEech, Geoffrey (1983): Principles of Pragmatics, London: Longman.

LÓPEz EIRE, Antonio (2003): La retórica en la publicidad, Madrid: Arco/Libros.

Lotman, Jurij M. (1985): La Semiosfera, Venezia: Marsilio.

MAgallón PORTOlÉs, Carmen (2014): «Universalizar legados femeninos, construir racionalidad civilizatoria: pasos hacia una cultura de paz», Cultura De Paz, 19/61. <https://www.revistasnicaragua.net.ni/index.php/culturadepaz/ article/view/563>.

MARCHESE, Angelo (1983): L'officina del racconto: semiotica della narratività, Milán: Mondadori.

Martín Salgado, Lourdes (2002): Marketing político, Barcelona: Paidós.

Mesa, Manuela y Laura Alonso CANo (2019-2020): «Narrativas y discursos en tiempos de pandemia: cómo explicar la crisis del COVID-19 desde el feminismo pacifista», Anuario CEIPAZ 2019-2020, 77-93.

OlzA, Inés (2020): «\#ReframeCovid: una iniciativa para pasar del marco lingüístico bélico sobre el coronavirus hacia otro que cohesione a la población», Vida Universitaria, 02/04/2020. <https://www.unav.edu/web/vida-universitaria/ detallenoticia6/2020/04/02/\% 23reframecovid:-una-iniciativa-para-pasar-delmarco-ling\% C3\% BCistico-belico-sobre-el-coronavirus-hacia-otro-que-cohesio ne-a-la-poblacion/-/asset_publisher/w7Px/content/2020_04_02_ics_reframe_ covid $/ 10174$ ?utm_source=Twitter\&utm_medium=social\&utm_campaign= General>.

ONG, Walter (1982): Orality and Literacy, Londres y Nueva York: Methuen.

Perelman, Chaime y Lucie Olbrechts-Tyteca (1989): Tratado de la argumentación, Madrid: Gredos.

Plantin Christian y Amparo Tusón (1996): La argumentación, París: Seuil.

Rodríguez GARCía, Sonia Ester (2008): «Connotación y persuasión en la imagen publicitaria», Gaceta de Antropología 24/2, 1-20.

SAlmon, Christian (2008): Storytelling. La fabbrica delle storie, Roma: Fazi Editore.

Santiago Guervós, Javier (2005): Principios de comunicación persuasiva, Madrid: Arco/Libros.

SCOLARI, Carlos Alberto (2013): Narrativas transmedia. Cuando todos los medios cuentan, Barcelona: Deusto.

Serrano, M. ${ }^{a}$ José y M. ${ }^{a}$ Isabel Hernández Toribio (2015): «¿Porque tú lo vales o porque lo vales? Variación de la segunda persona tú en los mensajes publicitarios», Ibérica 30, 105-128.

VAn Dıjk, Teun (1983): La ciencia del texto, Barcelona: Paidós. 


\section{APÉNDICE}

TABLA 1. Muestra de anuncios

\begin{tabular}{ll}
\hline \multicolumn{1}{c}{ Marca } & \multicolumn{1}{c}{ Enlace } \\
\hline AMENA & $<$ https://www.youtube.com/watch?v=vaDhA8e_7-w> \\
\hline ATRESMEDIA (1) & $<$ https://www.youtube.com/watch?v=_TxuPig2za8\&feature \\
& $=$ youtu.be
\end{tabular}




\begin{tabular}{|c|c|}
\hline EL POZO & $\begin{array}{l}<\text { https://www.youtube.com/watch?v=T8gR3Pum6gY\& } \\
\text { feature=youtu.be }>\end{array}$ \\
\hline ENDESA & $<$ https://www.youtube.com/watch?v=a0x0ptrZIX8> \\
\hline ESTRELLA GALICIA & $\begin{array}{l}<\text { https://www.youtube.com/watch?v=FDYOCz-OJBg\& } \\
\text { feature=youtu.be }>\end{array}$ \\
\hline FLORETTE & $\begin{array}{l}<\text { https://www.youtube.com/watch?v=tLaEfrtpVdw\&feature } \\
\text { =youtu.be }>\end{array}$ \\
\hline HYUNDAI & $<$ https://www.youtube.com/watch?v=wFHZcV6MHJA $>$ \\
\hline IKEA & $\begin{array}{l}<\text { https://www.youtube.com/watch?v=VaMQe0RO5PM\& } \\
\text { feature=emb_title }>\end{array}$ \\
\hline LEROY MERLIN & $<$ https://www.youtube.com/watch?v=JwecTVg1lLY> \\
\hline MAHOU & $\begin{array}{l}<\text { https://www.youtube.com/watch?v=03DjRllfBYY\&feature } \\
\text { =youtu.be }>\end{array}$ \\
\hline MAPFRE & $<$ https://www.youtube.com/watch?v=-zuRSL9HldM> \\
\hline MASTER CARD & $<$ https://www.youtube.com/watch?v=VKqo5jaK8IQ $>$ \\
\hline MCDONALD'S & $<$ https://www.youtube.com/watch?v=xraKscq7Lc4> \\
\hline $\begin{array}{l}\text { MCDONALD'S - } \\
\text { MCDELIVERYY MCAUTO }\end{array}$ & <https://www.youtube.com/watch?v=CEADDV91A_Y> \\
\hline 12.MESES MEDIASET (1) & $<$ https://www.youtube.com/watch?v=SllMxba39G4> \\
\hline 12.MESES MEDIASET (2) & $<$ https://www.youtube.com/watch?v=fujZtQ7Ivt4> \\
\hline 12.MESES MEDIASET (3) & $<$ https://www.youtube.com/watch?v=IlOdZT4HOVg > \\
\hline MOVISTAR & <https://www.youtube.com/watch?v=APcvMdQ2gEY> \\
\hline MUTUA MADRILEÑA & $\begin{aligned}<\text { https://www.youtube.com/watch?v=s2FnSIalY1k\&feature } \\
\\
=\text { emb_title }>\end{aligned}$ \\
\hline OFIMÁTICA & $<$ https://www.youtube.com/watch?v=e6XJ-Lw64Yk> \\
\hline ORANGE (1) & $<$ https://www.youtube.com/watch?v=8Wv-tWXgzcE $>$ \\
\hline ORANGE (2) & $\begin{aligned}<\text { https://www.youtube.com/watch?v=H-NsFpGYjb0\&.feature } \\
\\
\text { =emb_title }>\end{aligned}$ \\
\hline PALACIOS & $<$ https://www.youtube.com/watch?v=tMArnzAPPeI $>$ \\
\hline SANTALUCÍA SEGUROS & $\begin{array}{l}<\text { https://www.youtube.com/watch?v=PCDH6fxEYNY\& } \\
\text { feature=emb_title }>\end{array}$ \\
\hline SCHWEPPES & $<$ https://www.youtube.com/watch?v=xPUB5zdr1Xw> \\
\hline ŠKODA & $<$ https://www.youtube.com/watch?v=yAlDQnxLAHo > \\
\hline UNIVERSIDAD VIU & $<$ https://www.youtube.com/watch?v=jmm7B7zW6Cs $>$ \\
\hline VODAFONE (1) & $<$ https://www.youtube.com/watch?v=7ij1xNa8uhg $>$ \\
\hline VODAFONE (2) & $\begin{array}{l}<\text { https://www.youtube.com/watch?v=ANHJzXCY55Y\& } \\
\text { feature=emb_title }>\end{array}$ \\
\hline
\end{tabular}

